\section{CYCLOPROPANE ANESTHESIA}

By Benjamin Howard Robbins, B.A., M.S., M.D., Professor of Anesthesiology and Associate Professor of Pharmacology, Vanderbilt University School of Medicine. Second edition. Pp. 293. London: Baillière, Tindall \& Cox. $72 s$.

Anaesthetists and others interested in the scientific study of cyclopropane, will welcome this new edition of Dr. Robbins's book. About two-thirds of it is devoted to an excellent, detailed description of the pharmacological actions of this anaesthetic and is, in part, based upon the experimental work with which Dr. Robbins and his collaborators have been associated over the years. This enhances the value of the book to those doctors primarily concerned with the laboratory investigation of inhalational drugs, but, for the more clinically minded, each chapter finishes with a lucid and helpful summary of its contents. That part of the book devoted to the clinical aspects of cyclopropane anaesthesia is less valuable, perhaps because the passage of time has tended to modify the opinions quoted from some of the references. It also seems a pity that no mention is made of the pioneer work of Hingson in the U.S.A. and Bourne in this country on the use of cyclopropane in midget apparatus for minor operations, particularly on outpatients.

\section{PERIPHERAL NERVE INJURIES}

By Ruth E. M. Bowden. Pp. xiii +62 , with 30 diagrams. London: H. K. Lewis \& Co. Ltd. 1958. 8s. 6 d.

This book, only 57 pages long including 30 illustrations, answers a long-felt need for a short, concise textbook in the "introduction to methods of diagnosis and treatment of nerve injuries.' This is the task that Miss Bowden has set herself and she has succeeded well. It is expressly designed to 'meet the needs of physiotherapists, medical students and housemen and to be an aide memoire to their seniors.'

There are seven chapters in this book and, successively, they are: Classifications (9 pages), methods of examination and diagnosis (8 pages), electrodiagnosis (4 pages), anatomy (20 pages), treatment (5 pages), definitive surgical treatment (4 pages), and conservative treatment (6 pages).

It is not surprising to find the emphasis on anatomy since Miss Bowden is professor in that subject, and indeed the subject of peripheral nerve injuries demands accurate knowledge of anatomy. However, to devote 20 out of 57 pages to anatomy does seem a little unbalanced in a book designed for those who have recently studied anatomy. The plea for early diagnosis and reference to a specialist department would seem to be the main motive for this excellent book.

The commendable brevity and condensation of the material into 57 pages will form the chief attraction to undergraduate students whose time for reading specialist subjects is inevitably limited. The two hours spent in studying this book will be well worth while. On page 27 we find the phrase ' coalescence of one or more ganglia.' Must there not be two or more to form a coalescence?

It is to be hoped that this book will be widely read for if it leads to early diagnosis (and it is to the Casualty Officer that the problem is mainly presented in peacetime), and consequent treatment, better results can be expected. The book is well produced with good, clear type and bold illustrations, and at 8s. 6d. is not expensive.

\section{REHABILITATION OF THE HAND}

By C. B. WYNN-PARRY, M.B.E., M.A., D.M., D.Phys.Med. First Edition. Pp. vii +273 + index. London, Butterworth \& Co., Ltd. 1958. Price 45s.

Squadron-Leader Wynn-Parry calls his book Rehabilitation of the Hand, and of course the Hand is its main concern. Clearly though, it is impossible to separate the hand from the upper limb as a whole, and the author has very wisely avoided trying to make this artificial division. Indeed, his book covers the subject in its broader aspect so well that it might well be named Rehabilitation of the Upper Limb. The clear account of functional anatomy and of methods of examination is followed by useful sections dealing with injuries of tendons and of peripheral nerves. Complementary to the latter is the chapter on electrodiagnosis, in which an excellent and well-balanced account of these methods is given. Wynn-Parry's long experience and original work in this field have enabled him to make this chapter of real value and of great importance to all who have to deal with nerve injuries. Stiffness of the hand merits a separate chapter, in which the important causes of stiffness are considered and methods of treatment are described. Three further chapters deal with upper limb weakness, techniques of treatment and methods of resettlement, and D. A. Brewerton and D. $M$. Brooks contribute respectively excellent sections on the Rheumatoid Hand and on reconstruction of the injured hand.

Perhaps the two special merits of this important book are that it concentrates in one volume much that hitherto has had to be sought for in many books, and that it gives detailed descriptions of methods of treatment, of appropriate methods of occupational therapy and of the making of appliances. The author is of course very fortunately placed in being able to give a comprehensive account of rehabilitation of the injured hand from the time of injury to the time of final discharge. He and his colleagues have succeeded in doing this by efficient handling and good presentation of their large amount of material. As to the second special merit: all workers in this field will be grateful to SquadronLeader Wynn-Parry for the clear and comprehensive 
accounts of what to do and exactly how to do it. Perhaps this is' specially so in the final chapter dealing with Resettlement, in which a really excellent account is given of the facilities available and of the way to use them.

The work could hardly have been possible without the facilities provided by the Royal Air Force Medical Service, and it is greatly to the credit of those in charge of that Service that their foresight has made possible this important contribution. The author and his colleagues are to be congratulated on producing a book which is certain to become and remain required reading for all concerned with injuries of the hand in particular and with rehabilitation in general.

\section{LUNG FUNCTION TESTS}

By B. H. Bass, M.D., M.R.C.P. Pp. vii +72 with 17 illustrations. London: H. K. Lewis \& Co. Ltd. I959. 8s. 6d.

This very small book is presented, according to the preface, as an introduction to the principles of clinical pulmonary physiology and is not, as the title rather suggests, a description and critical assessment of lung function tests. It briefly outlines the essential components of normal respiration and indicates how each one can become deranged in disease and how attempts can be made to measure the extent of these derangements. It is very easily readable and must contain much that is new to those who have never studied respiratory diseases previously. However, the subject has been rather over simplified and a more critical approach would have been welcomed. This is especially 80 in the chapter on ventilation where some indices are presented as having an established position in lung function testing whereas they are rarely used in most centres in this country. Another criticism is that there are no references either to further reading in pulmonary physiology or to more detailed descriptions of the performance and limitations of the tests mentioned. These seem important omissions in any book purporting to be "an introduction."

W.B.T.

\section{ELECTROCARDIOGRAPHIC ANALYSIS}

\section{Vol. I}

\section{Biophysical Principles of Electrocardiography}

RoberT "H. Bayley, M.D. Pp. xvi + 237. London: Cassell \& Co. Ltd. 1958. 6os.

The author is an acknowledged leader in the field of electrocardiography and his research has yielded much information about the use of unipolar leads and vector analysis. His aim in this book is to provide an approach to the analysis of electro- cardiographic wave forms through a basic knowledg® of mathematics and electricity. His text is de $z$ veloped from his great experience of teaching af undergraduate and postgraduate levels.

The emphasis is placed on the appreciation of the importance of the electrical axis and vector analysis? during atrial and ventricular accession and regres sion of the electrical impulse. There follows av discussion of the changes associated with ventriculap hypertrophy, disease, drugs and injury. There isp an explanation of the triaxial reference system using both bipolar and unipolar leads which is of partits cular value in the assessment of the anatomical type of an atrial septal defect and when full vectot analysis is not undertaken.

The subject matter of this volume is beyond the scope of the general physican, but will be of value for those developing a specialized knowledge oß electrocardiography.

The value of Volume I as a basis for electro cardiographic analysis should be confirmed when Volume II ' Clinical Application of Electrocardio graphy' appears shortly. This will have speciaw reference to congenital heart disease.

\section{OBSTETRICAL PRACTICE}

By Alfred C. Beck, M.D., and Alexander $H_{0}$ Rosenthal, M.D. Seventh Edition. Pp. Wisi $+I_{1} 1_{5}$, illustrated. London: Baillière, Tind il \& Cox Ltd. I 958 . I i 2 S.

This is the Seventh Edition of the very wet established American book on Obstetric Practice It is, as can be seen, a large book and therefore contains, or should contain, a great deal about the practical details of the art and science of obstetric $\vec{s}$ It is fully illustrated with many line drawings and makes quite clear the mechanisms of most obstetrio deliveries and manoeuvres.

It is a little lop-sided in its writing. For instance brow presentation receives one scanty page, whereas ectopic pregnancy is dealt with fully from the pathological angle but not really quite adequately from the diagnostic and differential diagnostic angle. The book has an established place in American obstetrics and is a valuable reference book for the specialist obstetrician.

\section{CLINICAL OBSTETRICS AND}

GYNAECOLOGY, Vol. r, No. 3
'Abnormal Uterine Bleeding' edited by JoHN

\section{음} BREWER, M.D.; 'Special Diagnostic Aids edited by C. Paul Hodgkinson, M.D. Neeg York: Paul B. Hoeber, Inc. 1958.

This is the third section of the first volum presented in book form of the Clinical Obstetrios and Gynaecology series which appears four times year. This number is devoted in the main to 